\title{
EL PATRIMONIO HIDRÁULICO EN CHILE: CONSIDERACIÓN CULTURAL Y TURÍSTICA
}

\author{
Gregorio Castejón Porcel \\ Universidad de Alicante \\ https://orcid.org/0000-0001-7353-6082
}

\section{RESUMEN}

A pesar de los innumerable recursos de Chile, fundamentados en sus atractivos naturales, en su historia e importantes recursos arqueológicos y en una cultura con raíces indígenas milenarias, el patrimonio tangible e intangible ligado al agua, el patrimonio hidráulico, ha sido, poco estudiado, apenas considerado culturalmente como elemento de interés y pobremente promocionado por los organismos turísticos estatales. Situación incomprensible en un espacio en el que el control y aprovechamiento del agua mediante distintas infraestructuras e ingenios, ha sido, desde tiempos históricos, una cuestión de enorme transcendencia, tanto en los territorios de escasa e incluso nula pluviometría como en aquellos en los que los valores de precipitación son muy elevados.

Palabras clave: Patrimonio; patrimonio hidráulico; cultura hídrica; turismo; Chile.

\section{The hydraulic heritage in Chile: cultural and tourist consideration}

\section{ABSTRACT}

Despite the innumerable heritage of Chile, based on its natural attractions, in its history and important archaeological resources, and in a culture with thousands-year-old indigenous roots, the tangible and intangible heritage linked to water, the hydraulic heritage, has been scarcely studied, hardly considered culturally as an element of interest and poorly promoted by state tourism agencies. Incomprehensible situation in a space in which the control and the use of water through infrastructures and inventions, has been, since historical times, a matter of enormous importance, both in the territories of hydric scarce, and even zero rainfall, as in those in which the values of precipitation are very high.

Keywords: Heritage; hydraulic heritage; water culture; tourism, Chile.

Fecha de recepción: 10 de mayo de 2018

Fecha de aceptación: 30 de enero de 2019

Departamento de Geografía Humana. Universidad de Alicante. Apartado 99. 03080 ALICANTE (España). E-mail: gregorio.castejon@ua.es 


\section{INTRODUCCIÓN}

La superficie de Chile supera los $756.000 \mathrm{~km}^{2}$ y sobre esta se asientan más de 17,5 millones de personas de las que prácticamente la mitad residen en las grandes áreas metropolitanas de Santiago (6 mill.), Concepción (1 mill.), Valparaíso (1 mill.), La Serena (0,4 mill.) y Antofagasta ( 0,3 mill.). De este modo, la densidad poblacional apenas supera los $23 \mathrm{~h} / \mathrm{km}^{2}$, reflejo del vasto territorio que posee esta nación sudamericana, administrativamente dividida en quince regiones: Arica y Parinacota, Tarapacá, Antofagasta, Atacama, Coquimbo, Valparaíso, Metropolitana de Santiago, Libertador General Bernardo O’Higgins, Maule, Biobio, Araucanía, de Los Ríos, de Los Lagos, Aysén y Magallanes y Antártica chilena.

Se trata de un espacio con un sinfín de recursos naturales, históricos y culturales que son promocionados turísticamente, en mayor o menor medida, desde distintas instituciones locales, regionales y nacionales. En este sentido, teniendo en cuenta el gran número de recursos turísticos presentes en el país, el objetivo del presente trabajo es poner de manifiesto la consideración que se tiene del patrimonio hidráulico desde un punto de vista cultural y turístico, expresando, con ello, la visibilidad que estos elementos tienen en el territorio nacional.

Para la consecución de esta meta se ha realizado un análisis de los elementos catalogados como Monumentos Nacionales por el Consejo de Monumentos Nacionales (CMN) y de los Atractivos turísticos identificados por el Servicio Nacional de Turismo (SERNATUR), con la intención de identificar todos aquellos que están ligados al agua de un modo u otro, visualizando, así y de manera cuantitativa, el grado de percepción que ambas instituciones tienen de este patrimonio. Además, en una segunda fase de análisis, se ha procedido a definir aquellos bienes (tangibles e intangibles) que desde el SERNATUR y las Intendencias regionales de cada región del país se promocionan turísticamente, permitiendo, con ello, obtener una visión de la oferta turística que se ofrece desde estos organismos.

En base a los resultados obtenidos de los precitados exámenes, se concluye que, a día de hoy, el patrimonio hidráulico de Chile tiene una representación alarmantemente escasa, tanto en lo que respecta a los monumentos catalogados por el CMN como a los atractivos turísticos identificados por el SERNATUR y la oferta turística digital que se hace desde esta misma institución y las propias Intendencias regionales.

Este resultado llama la atención, por cuanto del análisis bibliográfico realizado sobre la materia, se extrae que existe un gran número de recursos ligados al patrimonio hidráulico que no se tienen en consideración, a pesar de tener una relevancia técnica, histórica y cultural de primer orden y a todas las escalas (local, regional, nacional e internacional), y pese a formar parte del patrimonio cultural de Chile, considerando la definición propuesta por el CMN que describe como tal a "un bien o conjunto de ellos que constituyen un legado o herencia que se traspasa de una generación a otra y que opera como testimonio de la existencia de nuestros antepasados, de sus prácticas y formas de vida. Esta amplia adscripción, comprende tanto las obras materiales (tangibles) como las interminables (intangibles), y a las cuales la sociedad otorga valor histórico, estético, científico o simbólico". 


\section{ESTADO DE LA CUESTIÓN}

Consultada la bibliografía próxima a la línea de trabajo del presente artículo, sorprende que exista tan solo un reducido número de estudios en los que se analiza el patrimonio hidráulico de Chile y, más concretamente, llama la atención la marcada carencia de trabajos relacionados con el posible uso de estos recursos como atractivos turísticos y potencial fuente de ingresos.

Sobresalen por su cantidad las aportaciones relativas a los molinos de agua de Chile; concretamente, son numerosos los estudios referidos a los complejos industriales edificados en Chiloé (Región de Los Lagos) redactados por Bravo et. al. (2016) y Sahady et. al. (2016 y 2017). Además, destacan los análisis correspondientes a la presencia de estos ingenios hidráulicos en la Región de O’Higgins (Bravo et. al. 2017 y 2018). Por otro lado, ocupando un área de estudio mayor, el trabajo de Rodríguez Domínguez (2015) versa, del mismo modo, sobre estas infraestructuras molineras e igualmente, es de gran interés la investigación de Sahady et. al. (2014) en la que, aparte de considerar los molinos de las distintas regiones de Chile, aborda la presencia de estos artefactos en la capital, Santiago, manifestando la existencia de las indicadas industrias en el señalado emplazamiento, al menos, desde el siglo XVI. Igualmente, cabe destacar la publicación de Sahady et. al. (2015) en la que se comparan estas industrias del país sudamericano con las de tipología similar edificadas en España en distintos momentos históricos y lugares.

Otro de los elementos estudiados con asiduidad en el mundo científico chileno se corresponde con las azudas (ruedas o norias) de Larmahue, en este caso, igualmente analizadas por el precitado grupo de investigadores, cuyos resultados han quedado recogidos en distintas aportaciones (Bravo et. al. 2013, 2015 y 2017; Sahady, 2011; Sahady et. al. 2013 a y b; y Sahady et. al. 2017), sin olvidar los trabajos previos de De las Casas (2007) y Soto (2011). Asimismo, cabe destacar la investigación de los mencionados autores en la que comparan las azudas de Chile con las norias españolas, en este caso en concreto con las de la Región de Murcia (Sahady et. al. 2013).

La exposición de la evolución histórica del aprovechamiento de las aguas de Chile, mediante la confección de distintas infraestructuras hidráulicas, supone un apartado de enorme interés en los trabajos de Sandoval Jeira (2003) y Astaburaga (2004), del mismo modo, que otras investigaciones han llevado a cabo un análisis, de carácter histórico, acerca de determinados proyectos de canalización promulgados hace siglos, como es el caso de Hidalgo (1985).

La gestión del agua, en lo que se refiere a su control, propiedad y distribución, o lo que es lo mismo, la administración y legislación que rigen el uso de este recurso, es, sin duda, otra de las cuestiones más estudiadas por los investigadores en el territorio de análisis. En este sentido, el conjunto de los trabajos de Dourojeanni (1999), Sandoval (2003), Astaburaga (2004), Arumi y Oyarzún (2006), Larraín (2006), Arumi et. al. (2014), Palerm Viqueira (2010) y Nicolás (2015), entre otros, permiten entender y completar una relación temporal de la distinta normativa que ha estado y está vigente en Chile en materia hídrica, así como hace posible obtener una visión de la manera de gestionar este bien, tanto de forma privada como estatal. Además, son especialmente 
interesantes, el considerable número de publicaciones en las que se indaga sobre la relevancia de las Organizaciones de Usuarios de Aguas (OUA) del país, caso de las aportaciones de Baeza (2008), Arroyo (2009), Arumi et. al. (2014) y Nicolás (2015).

Igualmente, donde la importancia de la cultura en el uso y manejo del agua es, sin duda, un rasgo diferenciador de los distintos grupos étnicos que poblaron el espacio que hoy configuran el territorio nacional, no extraña que parte de los estudios existentes pongan de manifiesto la excepcionalidad del valor etnográfico de los recursos culturales ligados al agua, siendo este el caso de la publicaciones de Orellana (2006), Martos y Martos (2013) y Pilquimán et. al. (2016). En esta línea, destacan aquellos trabajos que analizan una labor que, además de necesaria, para el buen funcionamiento de los sistemas de riego, resulta ser ya un ritual con un arraigado simbolismo, se trata de la limpia de los canales, actividad investigada por Bolados y Babidge (2017), así como también citada en numerosos apartados de las distintas aportaciones consultadas.

Llama la atención, igualmente, los análisis sobre el aprovechamiento hídrico en espacios de clima extremo, como es el caso del territorio bajo la influencia del desierto de Atacama (Hidalgo, 1985; Pourrut y Núñez, 1995; Flores, 2008; Hurtado, 2013 y Sepúlveda et. al., 2015); los referidos a las regiones áridas del norte andino de Castro (1997) y Castro et. al. (1991 y 1992) y, por último, los que tienen por marco de estudio espacios de clima semiárido, como es el valle del río Elqui (Erazo y Garay Flühmann, 2011) u otras extensiones más amplias. En esta línea, aunque fuera del criterio climatológico y tomando como marco de análisis distintas áreas de valles, se puede consultar el trabajo de Budds (2012) acerca del valle del río Ligua.

Con todo, sin lugar a dudas, del global de la bibliografía consultada, deben individualizarse aquellas publicaciones relativas a los distintos elementos hidráulicos que están, o estuvieron en algún momento, presentes en la capital de Chile, Santiago. En este sentido, en las aportaciones de Figueroa (2007, 2009, 2012 y 2014), Hidalgo y Vila (2015), Rosas y Pérez (2013) y Márquez y Trufello (2013), se describen parte de los distintos canales y acequias que distribuían las aguas captadas en los cursos fluviales próximos para su uso humano y agrícola en la urbe y terrenos colindantes; red que a finales del XIX, debido a los problemas de salubridad existentes por su uso como cloaca comunitaria, fue reformulada como una nueva red alcantarillado y evacuación de las aguas pluviales, como ponen de manifiesto, entre otros, Pérez et. al. (2013) y Fernández (2015).

Por último, teniendo en cuenta lo expuesto hasta ahora, la existencia de un catálogo de infraestructuras hidráulicas es una quimera, más si cabe, si este intenta recopilar tanto los elementos físicos como la cultura intangible ligada a cualquier bien de patrimonio hidráulico. No obstante, en lo relativo a la parte tangible o física de esta riqueza arquitectónica y etnográfica, Sandoval (2003) logra un amplio inventario regionalizado de las obras hidráulicas construidas entre 1939-2000 en el amplio territorio de Chile; recopilación en la que destacan la presencia de canales, embalses y sistemas de irrigación asociados a valles de diferenciada extensión y disponibilidad hídrica. 


\section{METODOLOGÍA Y FUENTES}

En primer lugar, es necesario afirmar que para una mejor comprensión y presentación de los resultados del presente estudio, se ha procedido a dividir el espacio geográfico de Chile en tres zonas: Zona norte (Regiones Arica y Parinacota, Tarapacá, Antofagasta, Atacama y Coquimbo); Zona central (Valparaíso, Metropolitana de Santiago, Libertador General Bernardo O'Higgins, Maule y Biobio); y, por último, Zona sur (Araucanía, de Los Ríos, de Los Lagos, Aysén y Magallanes y antártica chilena).

En lo que se refiere al trabajo de investigación, en primera instancia, se ha procedido a realizar un análisis bibliográfico como fuente de información para conocer el estado de la cuestión de la temática de estudio, así como herramienta para identificar los trabajos publicados que analizan el valor patrimonial de cualquier infraestructura o edificación hidráulica y cualquier elemento cultural ligado al agua de carácter inmaterial y material susceptible de ser considerado patrimonio.

Como método de individualización de los elementos patrimoniales catalogados por el Gobierno de Chile, se ha recurrido a la consecución y análisis de la relación de bienes monumentales confeccionada por el CMN, dependiente del Ministerio de las Culturas, las Artes y el Patrimonio, mientras que para la caracterización de los atractivos turísticos del país se ha apelado al catálogo realizado por el SERNATUR, dependiente del Ministerio de Economía, Fomento y Turismo. En ambos casos, a partir de la relación total, se ha llevado a cabo una identificación de aquellos monumentos o elementos relacionados con el patrimonio hidráulico, tanto de carácter inmueble y físico como intangibles.

Seguidamente, a partir de la singularización de los monumentos de carácter hidráulico y los atractivos turísticos ligados a la cultura del agua, se ha procedido a realizar un tratamiento estadístico y una representación gráfica de los resultados como herramienta de expresión del grado de estima del patrimonio hidráulico dentro del conjunto de bienes considerados como monumentos y de aquellos supuestos como atractivos turísticos.

A continuación, se ha hecho un vaciado de los elementos turísticos promocionados en los portales digitales del SERNATUR (Chile es tuyo: https://www.chileestuyo.cl/ y Chile travel: http://chile.travel/) de cada una de las quince regiones de Chile, así como de los servicios digitales de cada una de las Intendencias regionales. Al igual que en el caso anterior, una vez identificados los elementos turísticos promocionados relacionados con el patrimonio hidráulico del país, se ha realizado un tratamiento estadístico y una representación gráfica de los resultados como herramienta de manifestación de la relevancia de estos elementos dentro de la promoción turística nacional.

Finalmente, considerando los resultados obtenidos y el análisis bibliográfico elaborado, se ha resuelto la consideración real que se tiene, cultural y turísticamente, del patrimonio hidráulico en el área de estudio. Además, en base a los numerosos elementos patrimoniales identificados en la lectura de la bibliografía, se han realizado una serie de propuestas encaminadas a la mejora de la identificación, protección y promoción de bienes, pese a que, a día de hoy, no sean considerados atractivos turísticos por el SERNATUR, ni destacados como Monumentos por el CMN, ya que, pese a ello, son bienes de interés, tanto para la comunidad científica como para el resto de la población, y, sin duda, son susceptibles de explotación turística. 


\section{BIENES CATALOGADOS POR EL CONSEJO DE MONUMENTOS NACIO- NALES}

El CMN es el organismo encargado, desde su creación en 1925, de la protección del patrimonio cultural y natural de Chile, y el único que tiene potestad para identificar y declarar como Monumentos Nacionales los bienes culturales y naturales que son susceptibles de tal consideración en base a la Ley N 17.288 de Monumentos Nacionales de 1970; normativa que distingue, a su vez, entre cinco categorías de monumentos: Monumentos históricos, Monumentos públicos, Zonas típicas, Santuarios de la Naturaleza y Monumentos Arqueológicos.

En base a lo indicado, para el desarrollo del presente trabajo es ineludible tomar en consideración la relación de monumentos formulada por esta institución con el objetivo de diferenciar del cómputo global, aquellos relacionados con el agua. En este sentido, de un total de 1689 monumentos catalogados (CMN, 2018), tan solo 65 guardan relación con el citado elemento, es decir, un $3,8 \%$, y todos ellos pertenecen a la categoría de monumentos históricos. De este modo, la representación del patrimonio hidráulico en el conjunto de bienes considerados como monumentos nacionales en Chile, es extremadamente limitada.

$\mathrm{Al}$ analizar estos 65 monumentos, se percibe que existe una diversidad tipológica reducida, con tan solo diez tipologías diferenciadas, entre las que destacan sobre el total, de manera notable, tanto puentes (24) como azudas (17), ya que constituyen el grueso del conjunto, con valores muy por encima del resto; le siguen: acueductos (7), fuentes (5), espejos de agua (5), viaductos y piletas o pilas de agua (2), y, por último, con un valor único (1): tubería, tranque y central hidroeléctrica.

En lo que se refiere a los primeros, existe un reparto, relativamente, equitativo entre las infraestructuras construidas en piedra y aquellas edificadas mediante el uso del hierro, estas últimas, en su mayoría, formando parte indispensable de distintas líneas ferroviarias. Por el contrario, el total de azudas se corresponden con las existentes en el Canal de Larmahue de Pichidegua (Provincia de Cachapoal). En tercer lugar, se identifica el Acueducto de Amolanas edificado en Tierra Amarilla (Provincia de Copiapó) ${ }^{1}$, al que siguen los Espejos de Agua de la Plaza de Armas de Angol (Provincia de Malleco), la Fuente central de la Plaza de Armas de Copiapó (Provincia de Copiapó), las piletas del Niño Pez en Lebu (Provincia de Arauco) y la de la Plaza del pueblo de Zapallar (Provincia de Petorca), los Viaductos de Conchi en Calama (Provincia del Loa) y del Malleco en Collipulli (Provincia del Malleco), la Tubería de madera de Pangal en la comuna de Machalí (Provincia de Cachapoal), el Tranque Sloman en la comuna de María Helena (Provincia de Tocopilla) y, por último, la Planta Hidroeléctrica de Chivilingo en Lota (Provincia de Concepción).

Si además de evaluar la tipología se examina la distribución en el territorio de Chile de los monumentos nacionales, tanto en su totalidad como individualizando aquellos ligados al patrimonio hidráulico (Figura 1), se extrae una información ciertamente interesante.

En lo que se refiere al conjunto global de monumentos distinguidos por el CMN, se observa una mayor concentración de los citados bienes en la zona central, donde su dis-

1 Cabe señalar que, pese a que aparece citado en siete ocasiones, todas ellas se refieren al mismo elemento. 


\section{Figura 1 \\ DISTRIBUCIÓN DE LOS MONUMENTOS NACIONALES EN CHILE E INDIVIDUALIZACIÓN DE AQUELLOS LIGADOS AL AGUA}

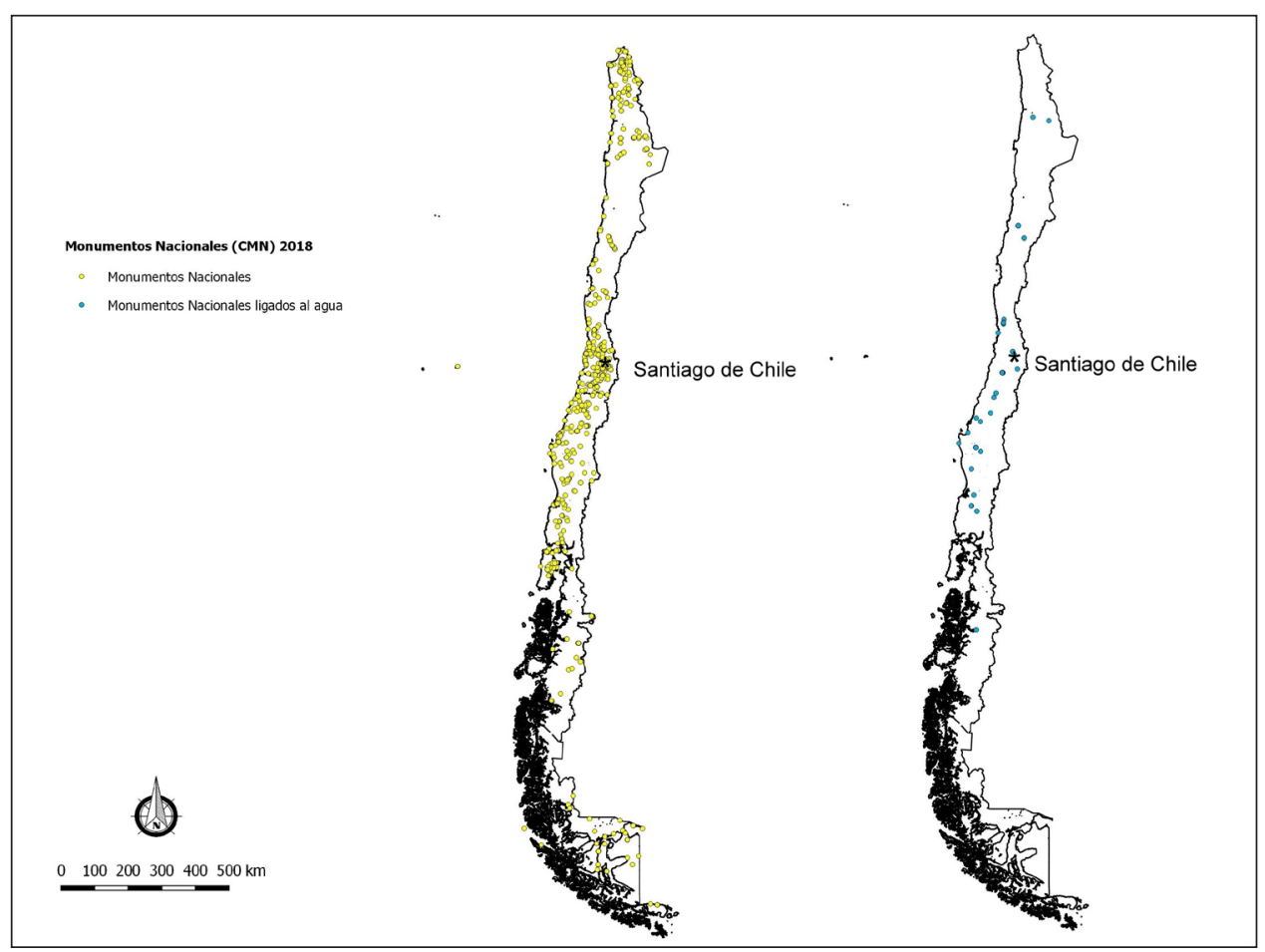

Fuente: Elaboración propia a partir de los datos del CMN.

tribución es bastante homogénea en las regiones que la conforman. En la zona norte, la agrupación más numerosa se halla en las Regiones de Arica y Parinacota y Tarapacá, en el área norteña, mientras que, en lo que se refiere a la zona sur del país, se aprecia una mayor existencia de monumentos en la parte meridional, Región de la Araucanía y Región de Los Lagos, si bien se intuye también cierta concentración entorno a Punta Arenas en la Región de Magallanes y la Antártica chilena.

En el caso de la localización de aquellos bienes considerados monumentos nacionales y que guardan una estrecha relación con el agua, cabe decir que, igualmente, presentan una mayor concentración en la zona central (34), si bien, aunque reducida, tienen una representación considerable en la zona norte (19) y algo más escasa en el sur (12). Así, un 29,2\% de los bienes históricos considerados monumentos nacionales y que están relacionados con el agua se hallan en la zona norte, más de la mitad $(52,3 \%)$ en el territorio central y, por último, y con una cifra menor que el resto, tan solo el 18,5\% en las regiones de la zona sur. 


\section{ATRACTIVOS TURÍSTICOS IDENTIFICADOS POR EL SERNATUR}

La siguiente fuente de información para valorar la atención prestada al patrimonio hidráulico en Chile, como recurso cultural y turístico, es la relación de Atractivos turísticos del SERNATUR.

El citado organismo público, creado en 1975, tiene por fin investigar, planificar, fomentar, controlar, promover y coordinar la actividad turística de Chile en base a la Ley Orgánica $\mathrm{N}^{\circ} 1.224$ del Ministerio de Economía, Ley de Turismo N²0.423; así, según señala, este tiene por objeto "ejecutar planes y/o programas basados en la Política Nacional de Turismo, impulsando el desarrollo sustentable de la actividad turística, incentivando la especialización, la calidad y la competitividad de la industria y promocionando los destinos y atractivos turísticos nacionales, para contribuir al desarrollo económico, social y cultural del país”. Además, cabe decir que, estructuralmente, se trata de una institución que cuenta con representación en todas las regiones del país a través de las Direcciones Regionales de Turismo, por lo que tiene un conocimiento amplio y en superficie del extenso territorio que conforma Chile, lo que, a priori, debe garantizar la consideración completa de todos aquellos elementos relevantes y turísticamente atractivos.

En base a esto, la relación de Atractivos turísticos confeccionada por este organismo se compone de 4413 elementos $^{2}$, distribuidos de la siguiente manera: 1334 (30\%) en la zona norte, 1748 (40\%) en la zona centro y 1331 (30\%) en la zona sur. De igual modo, analizado el citado listado, se deduce que del total de atractivos para cada zona, aquellos que guardan relación con el agua suman un total de 138 (el 3,13\% del total), en este sentido destaca la zona sur con un $41 \%$ de los 138 consignados, seguida de cerca por el centro con un $38 \%$ y a una distancia mayor, el norte, con un $21 \%$.

Cartográficamente, la distribución de ambas variables según zona, proporciona una visión interesante que permite estimar las áreas de mayor concentración de atractivos turísticos, de lo que, a su vez, se deducen las zonas con una mayor promoción turística, que coinciden, generalmente, con las de mayor atractivo, si bien pueden existir elementos interesantes que no sean explotados, como puede ser el caso del patrimonio hidráulico.

Además, si se analiza la localización de estos atractivos ligados al agua y la de los principales circuitos turísticos identificados por el SERNATUR (Figura 2), llama la atención que un alto porcentaje se encuentran emplazados en áreas próximas a las principales rutas y circuitos turísticos identificados por el precitado organismo estatal, lo que no significa su integración total en los mismos. En la zona norte, se ubican en la zona próxima a la Ruta del Desierto y los Circuitos del Chungará, Quebradas y Desiertos. En la zona central, sorprendentemente, apenas se señalan circuitos turísticos y, por tanto, su relación con los atractivos es nula. Por último, en la zona sur, comparten espacio con la Ruta Interlagos y los Circuitos Araucanía Andina, Lacustre, Cuenca del Lago Ranco, Nor Patagonia y Siete Lagos; con la Ruta Originaria y los Circuitos Lafken Mapu, Lago Budi y Nahuel-

2 La relación está estructurada de manera excelente, organizando los atractivos según Categoría, Tipo y Subtipo, incluyendo información relativa al nombre del atractivo, región, provincia, comuna y localidad donde se encuentra, además de una descripción, dirección, teléfono, propiedad, administración, estacionalidad, uso turístico, demanda, estado de conservación y otros datos de interés. 
buta; con la Ruta de la Carretera Austral y los Circuitos Melinka y Canales Patagónicos y Transversal Coyhaique-Puerto Aysén-Chacabuco; y, en último lugar, la Ruta del Mar y el Circuito Selva Valdiviana.

Figura 2

DISTRIBUCIÓN DE LOS ATRACTIVOS LIGADOS AL AGUA Y CIRCUITOS TURÍSTICOS DEFINIDOS

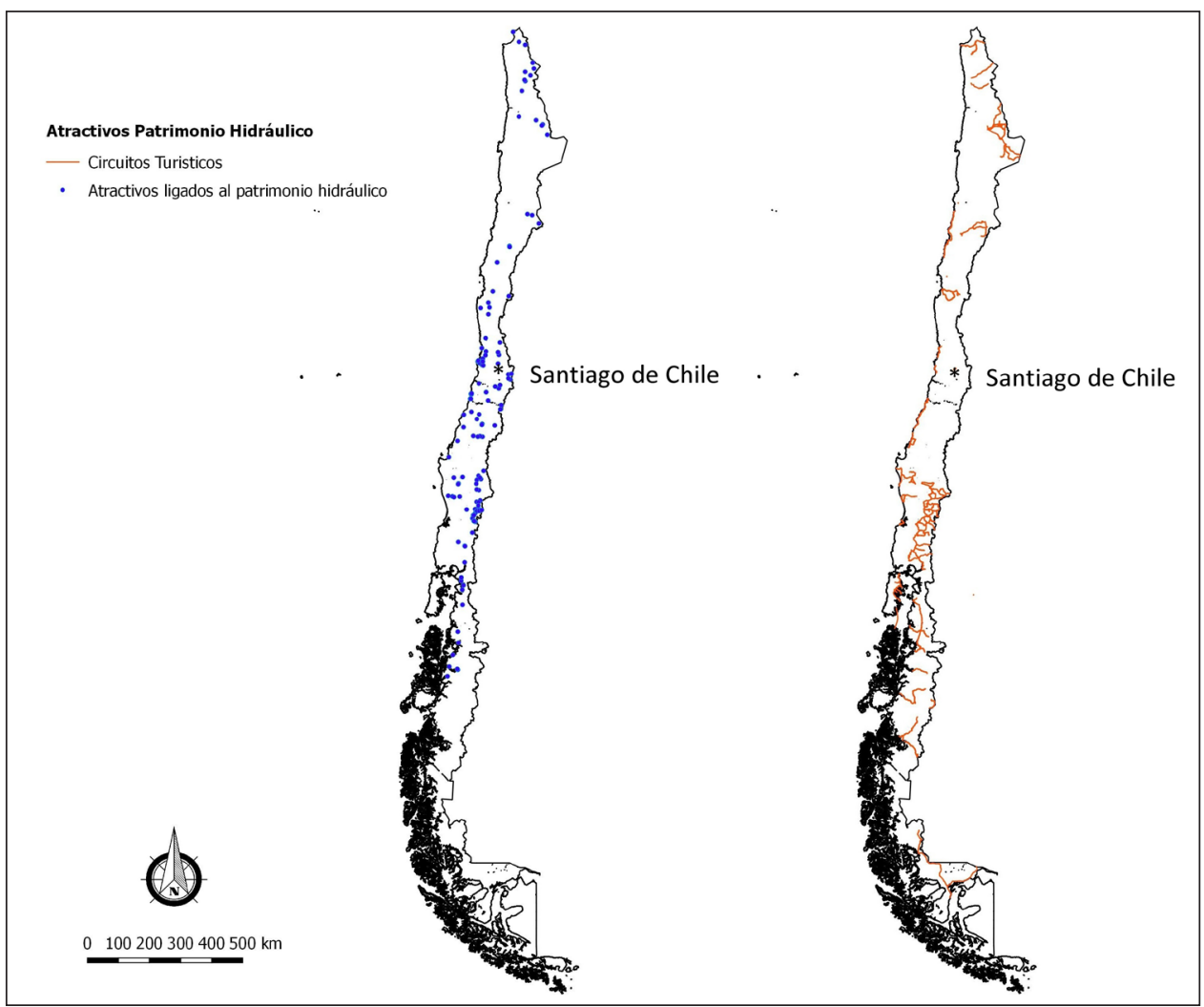

Fuente: Elaboración propia a partir de los datos del SERNATUR.

\subsection{Zona norte}

Si se observa la Figura 3 (a), se aprecian claramente seis áreas con mayor concentración de atractivos, destacando notablemente sobre estas, el sector norte (Arica, Parque Nacional Lauca, Belén, Iquique y valle de la Quebrada de Tarapacá) y sur (Coquimbo, La Serena y el Valle del Elqui). Con valores menos cuantiosos que los de estos dos espacios señalados, pero destacando sobre el resto del territorio, se encuentran las cuatro áreas restantes que se corresponden con Antofagasta, San Pedro de Atacama, Caldera y Copiapó, y Los Vilos. 
Figura 3

DISTRIBUCIÓN ESPACIAL EN LA ZONA NORTE DE CHILE DEL TOTAL DE LOS ATRACTIVOS TURÍSTICOS (a) Y DE AQUELLOS RELACIONADOS CON EL PATRIMONIO HIDRÁULICO (b)

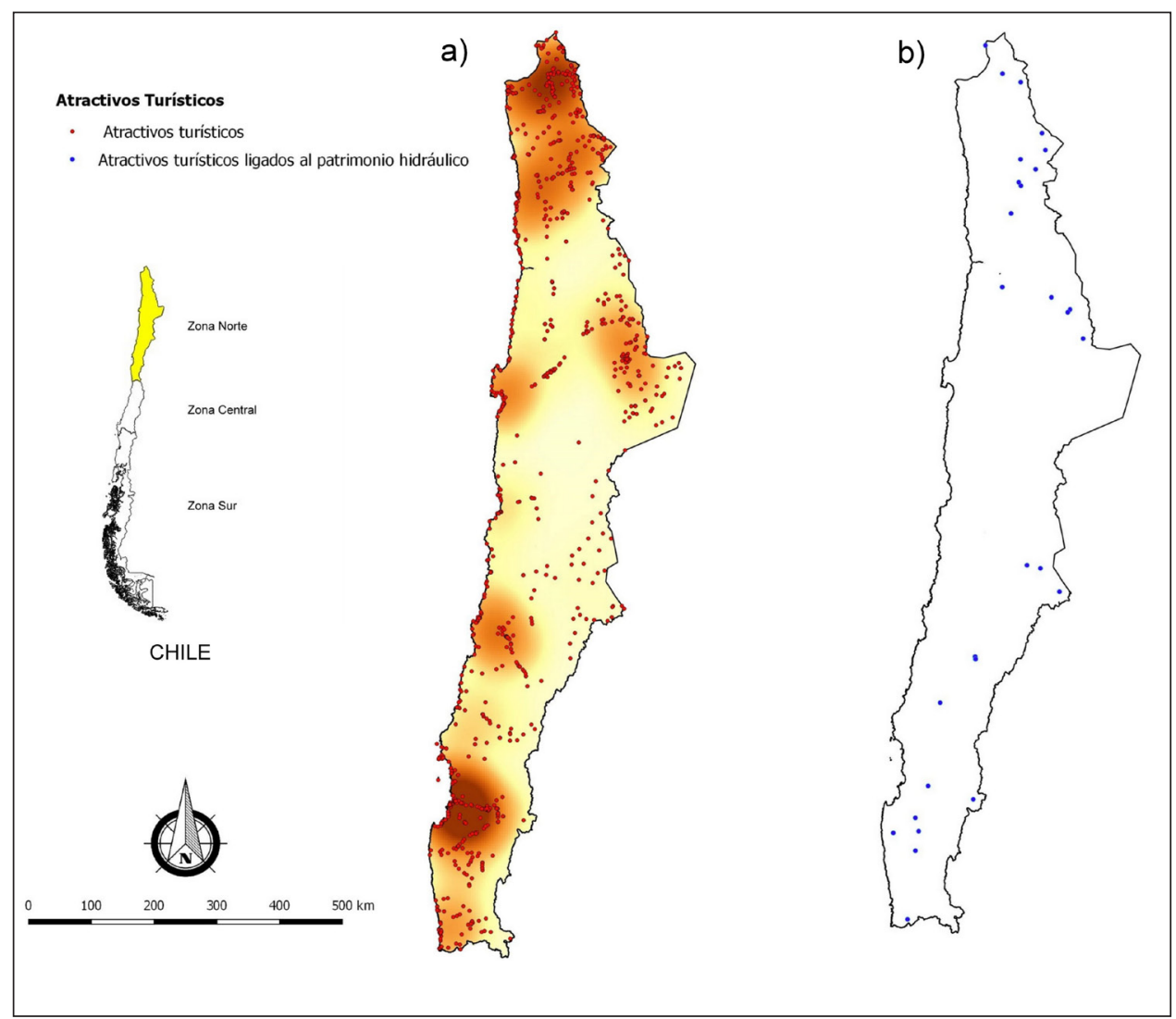

Fuente: Elaboración propia a partir de los datos de SERNATUR.

En lo que se refiere a los atractivos turísticos ligados al patrimonio hidráulico (Tabla 1), su localización es bastante dispersa (Figura 3, b) ya que estos se sitúan en distintos puntos del territorio del área distinguida como tal. Sobre el total de atractivos turísticos incluidos en la relación del SERNATUR, estos últimos únicamente constituyen el 2,2\% con una cifra de 29 de una suma de 1334; valor que, sin duda, es casi insignificante.

Del examen de tipologías de los citados atractivos (Figura 4) se deduce que prácticamente la mitad son termas (14), a las que siguen de cerca en número los embalses (10), y con valores muy reducidos tranques (2) y molino hidráulico, cultivo tradicional en terrazas, oasis y acueducto (1). 
Tabla 1

ATRACTIVOS TURÍSTICOS LIGADOS AL PATRIMONIO HIDRÁULICO
SEGÚN ZONA

\begin{tabular}{|c|c|c|}
\hline ZONA NORTE & ZONA CENTRAL & ZONA SUR \\
\hline $\begin{array}{l}\text { Termas de Enquelga } \\
\text { Termas de Macaya } \\
\text { Termas de Mamiña } \\
\text { Oasis Puquio de Nuñez } \\
\text { Termas de Ancuaque } \\
\text { Termas de Chusmiza } \\
\text { Termas de Lirima } \\
\text { Termas de Socos } \\
\text { Embalse La Laguna } \\
\text { Embalse Recoleta } \\
\text { Embalse La Paloma } \\
\text { Embalse Cogotí } \\
\text { Embalse Culimo } \\
\text { Embalse Puclaro } \\
\text { Termas de Churiguaya } \\
\text { Termas de Jurasi } \\
\text { Termas Aguas Calientes } \\
\text { Termas de Juncalito } \\
\text { Acueducto de Amolanas } \\
\text { Embalse Lautaro } \\
\text { Tranque La Ola } \\
\text { Termas de Laguna Verde } \\
\text { Molino de Las Juntas } \\
\text { Embalse Santa Juana } \\
\text { Baños de Turi } \\
\text { Tranque Sloman (Mh) } \\
\text { Termas de Puritama } \\
\text { Embalse y Puente Conchi } \\
\text { Ayquina y terrazas de cultivo }\end{array}$ & $\begin{array}{l}\text { Central Hidroeléctrica Ralco } \\
\text { Puente viejo sobre el río Itata (Mh) } \\
\text { Termas de Nitrao } \\
\text { Planta Hidro. de Chivilingo (Mh) } \\
\text { Central Hidroeléctrica Pangue } \\
\text { Termas del Avellano } \\
\text { Termas de Panimavida } \\
\text { Termas de Quinamavida } \\
\text { Termas de Catillo } \\
\text { Embalse Bullileo } \\
\text { Embalse Digua } \\
\text { Embalse Tutuven } \\
\text { Baños El Medano } \\
\text { Baños termales Gualleco } \\
\text { Salinas de Boyeruca } \\
\text { Puente sobre el río Pangue (Mh) } \\
\text { Puente sobre el río Maule (Mh) } \\
\text { Puente Ferroviario Banco de Arena } \\
\text { Puente de Perquilauquen (Mh) } \\
\text { Baños de San Pedro } \\
\text { Termas de Cauquenes } \\
\text { Termas del Flaco } \\
\text { Salinas de Cahuil } \\
\text { Embalse Convento Viejo } \\
\text { Caballo de agua E.F. Lingue (Mh) } \\
\text { Salinas de Lo Valdivia } \\
\text { Azudas de Larmahue (Mh) } \\
\text { Central Hidroelétrica Rapel } \\
\text { Fiesta Ruedas De Larmahue } \\
\text { Acueducto de cal y canto } \\
\text { Museo de sitio Los Canales } \\
\text { Ruta de San Andrés } \\
\text { Embalse Collahue } \\
\text { Salinas de Pullally } \\
\text { Embalse Poza Azul } \\
\text { Tranque Sauzal } \\
\text { Tranque Las Cenizas } \\
\text { Tranque La Luz } \\
\text { Puentes Acueducto Peñuelas } \\
\text { Embalse Laguna El Chepical } \\
\text { Tranque Lo Orozco } \\
\text { Tranque Lo Ovalle } \\
\text { Termas El Corazón } \\
\text { Termas de Jahuel } \\
\text { Puente Colgante Lo Rojas } \\
\text { Tranque El Recreo } \\
\text { Fuente de Neptuno } \\
\text { Embalse Los Aromos } \\
\text { Termas de Colina } \\
\text { Baños Colina } \\
\text { Embalse El Yeso } \\
\text { Termas del Plomo } \\
\text { Baños Morales }\end{array}$ & $\begin{array}{l}\text { Tranque Santa Elena } \\
\text { Termas de Pemehue } \\
\text { Tranque El Castillo } \\
\text { Molino de Traiguén } \\
\text { Termas de Tolhuaca } \\
\text { Termas de Manzanar } \\
\text { Puente Pte. Eduardo Frei Montalva } \\
\text { Puente Ferroviario Río Cautín } \\
\text { Puente Ragñintuleufu } \\
\text { Termas de Huechelepun } \\
\text { Termas de Quimey-Co } \\
\text { Termas Los Pozones } \\
\text { Termas de Huife } \\
\text { Termas de Liucura } \\
\text { Puente Rodrigo De Bastidas } \\
\text { Termas de Menetue } \\
\text { Termas de San Luis } \\
\text { Termas Recuerdo De Ancamil } \\
\text { Termas de Palguin } \\
\text { Viaducto del Malleco (Mh) } \\
\text { Termas de Balboa o Molulco } \\
\text { Termas de Queipue o Alpehue } \\
\text { Termas de Malalcahuello } \\
\text { Termas de Panqui } \\
\text { Termas de río Blanco } \\
\text { Puente sobre el Chol Chol (Mh) } \\
\text { Termas de Chihuio } \\
\text { Termas de Conaripe } \\
\text { Termas de Liquiñe } \\
\text { Termas Geométricas } \\
\text { Termas de Vergara } \\
\text { Eco Termas Pellaifa } \\
\text { Termas de Manquecura } \\
\text { Termas río Liquiñe } \\
\text { Puente Chirre } \\
\text { Termas Carranco } \\
\text { Termas del Rincón } \\
\text { Termas Hipólito Muñoz } \\
\text { Termas Punulaf } \\
\text { Termas Rayenco } \\
\text { Termas Trafipan } \\
\text { Termas de Quitralco } \\
\text { Termas de Puyuhuapi } \\
\text { Termas Puerto Bonito } \\
\text { C. Hidroeléctrica río Los Palos } \\
\text { Termas Puerto Pérez } \\
\text { Termas Valle Marta } \\
\text { Puente Presidente Ibañez (Mh) } \\
\text { Termas de Aguas Calientes } \\
\text { Termas de Ralun } \\
\text { Termas El Amarillo } \\
\text { Termas de Puyehue } \\
\text { Termas de Llancahue } \\
\text { Termas de Cahuelmo } \\
\text { Termas de Porcelana } \\
\text { Termas de Pichicolo }\end{array}$ \\
\hline
\end{tabular}

Fuente: Elaboración propia a partir de los datos de SERNATUR. 


\section{Figura 4 \\ ATRACTIVOS TURÍSTICOS LIGADOS AL AGUA EN LAS ZONAS NORTE, CENTRAL Y SUR SEGÚN TIPOLOGÍA}

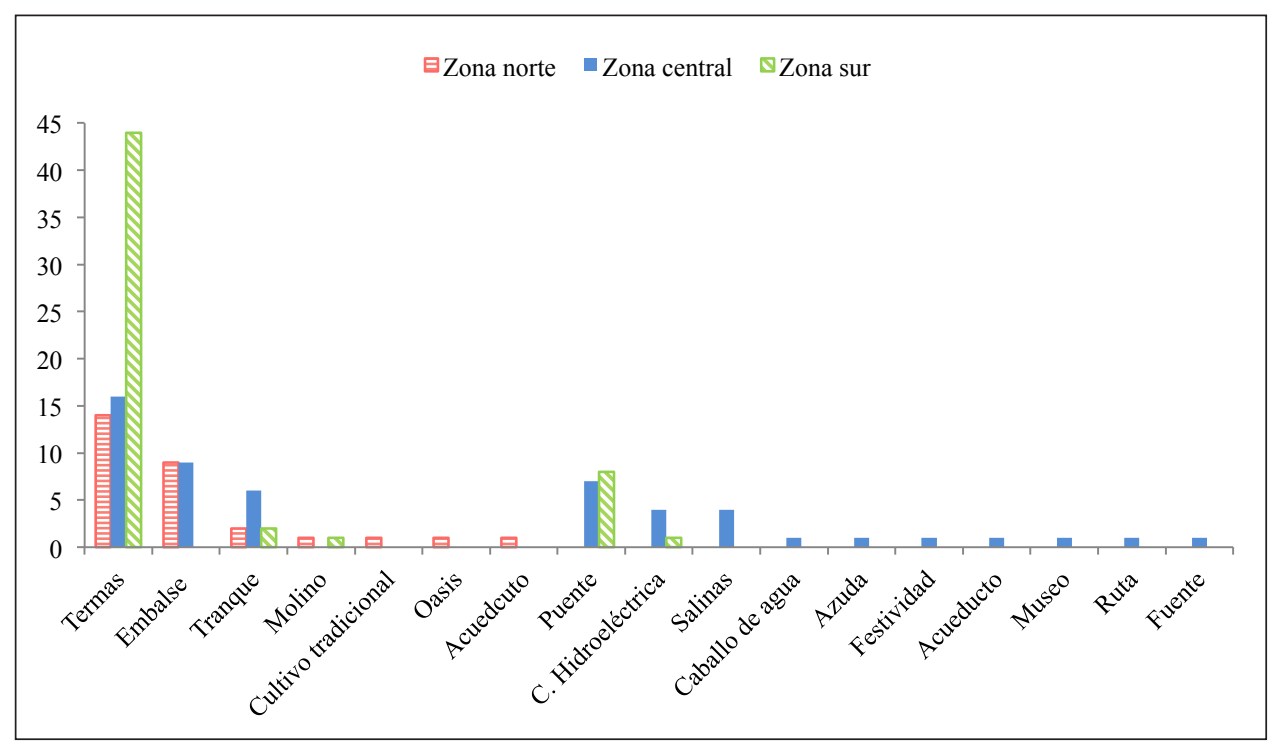

Fuente: Elaboración propia a partir de los datos de SERNATUR.

\subsection{Zona central}

Al contrario de lo que ocurre en la zona norte, en el caso de la zona central de Chile, la concentración de los atractivos se encuentra muy localizada en la capital nacional, Santiago, y su área circundante (Figura 5, a), extendida a la costa de Valparaíso y San Antonio. Al sur de la capital, destaca el área de Rancagua, cuenca de Cachapoal y río Tinguiririca, extensible incluso a la cuenca del río Maule, ya en el centro del área establecida. De este modo, se aprecia un llamativo descenso gradual del número de atractivos turísticos estimados desde el norte hacia el sur de la zona central de Chile.

En este caso, en lo referente a los atractivos turísticos ligados al patrimonio hidráulico (Tabla 1), su localización es bastante homogénea (Figura 5, b), con un importante número concentrado en el área comprendida entre Valparaíso, Casa Blanca y Villa Alemana, si bien en términos globales se aprecia un gran vacío en el sector suroeste de la definida como zona central. Del total de atractivos turísticos incluidos en la relación del SERNATUR, aquellos ligados al agua en la precitada zona, únicamente constituyen el 3\%, con una cifra de 53 elementos de un total de 1778; valor que, al igual que ocurría en el norte, es, nuevamente, insignificante.

Tipológicamente (Figura 4), en la zona central existe una mayor número de bienes diferenciados que en el caso de la zona norte. En concreto, mientras que en la primera área esta variedad se reducía a siete categorías, en el centro del país se amplía a trece, 
aunque, en ambos casos, termas (16) y embalses (9), suponen los elementos con mayor número dentro del espacio tratado. A estos les siguen los puentes (7), tranques (6), centrales hidroeléctricas y salinas (4), y con cifras unitarias, las azudas (aunque sean 17 las existentes), el caballo de agua, las festividad de las Ruedas de Larmahue, un acueducto, un museo, una ruta turístico/cultural y una fuente.

\section{Figura 5}

DISTRIBUCIÓN ESPACIAL EN LA ZONA CENTRAL DE CHILE DEL TOTAL DE LOS ATRACTIVOS TURÍSTICOS (a) Y DE AQUELLOS RELACIONADOS CON EL PATRIMONIO HIDRÁULICO (b)

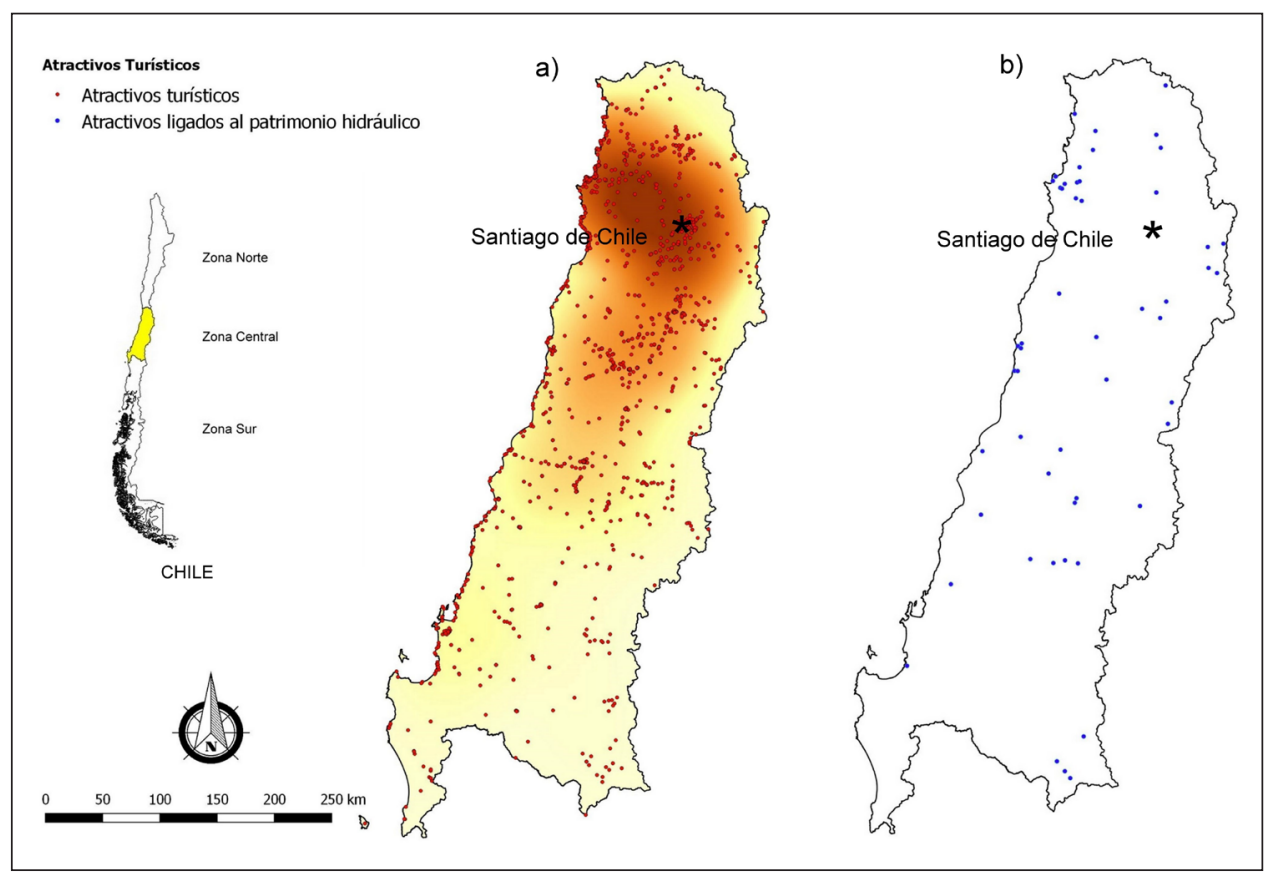

Fuente: Elaboración propia a partir de los datos de SERNATUR.

\subsection{Zona sur}

Por último, en la zona sur, los atractivos turísticos están claramente localizados, preferentemente, en el sector norte (Figura 6, a), con especial relevancia en el área comprendida entre Pucón, Linca Ray y los Parques Nacionales Villarrica y Huerquehue; la zona costera entre Puerto Saavedra y Pedro de Valdivia; los diferentes lagos existentes entre Pucón y Puerto Montt y, finalmente, el Archipiélago de Chiloé. Por otro lado, como concentraciones secundarias destacan el arco conformado por Puerto Aysén, Reserva Nacional Río Simpson, Coyahique y Reserva Nacional Cerro Castillo; el Parque Nacional Laguna San Rafael y el Parque Nacional Torres del Paine. 
En lo que concierne a los atractivos turísticos ligados al patrimonio hidráulico existente en las regiones que componen esta área de estudio (Tabla 1), cabe señalar que, prácticamente la totalidad de estos, se encuentran en la mitad septentrional del espacio indicado (Figura 6, b), destacando los ubicados en las inmediaciones de Pucón y las Reservas Nacionales de Huerquehue y Villarrica, y, en grado menor, en la zona comprendida entre Collipulli y Temuco, al norte. El resto suponen elementos aislados al sur de ambas concentraciones destacadas. En este caso, del total de atractivos turísticos incluidos en la relación del SERNATUR, aquellos ligados al agua en la zona sur, escasamente constituyen el 4,2\%, con una cifra de 56 elementos del global total de 1331; valor superior al de las zonas norte y central pero que del mismo modo es apenas significativo.

Del análisis tipológico de los atractivos ligados al patrimonio hidráulico (Figura 4), se deduce una conclusión clara en la zona sur: la variedad es muy limitada y las termas son el elemento hegemónico (44) sobre el resto de atractivos, puentes (8), tranques (2), central hidroeléctrica (1) y molino (1).

Figura 6

DISTRIBUCIÓN ESPACIAL EN LA ZONA SUR DE CHILE DEL TOTAL DE LOS ATRACTIVOS TURÍSTICOS (a) Y DE AQUELLOS RELACIONADOS CON EL PATRIMONIO HIDRÁULICO (b)

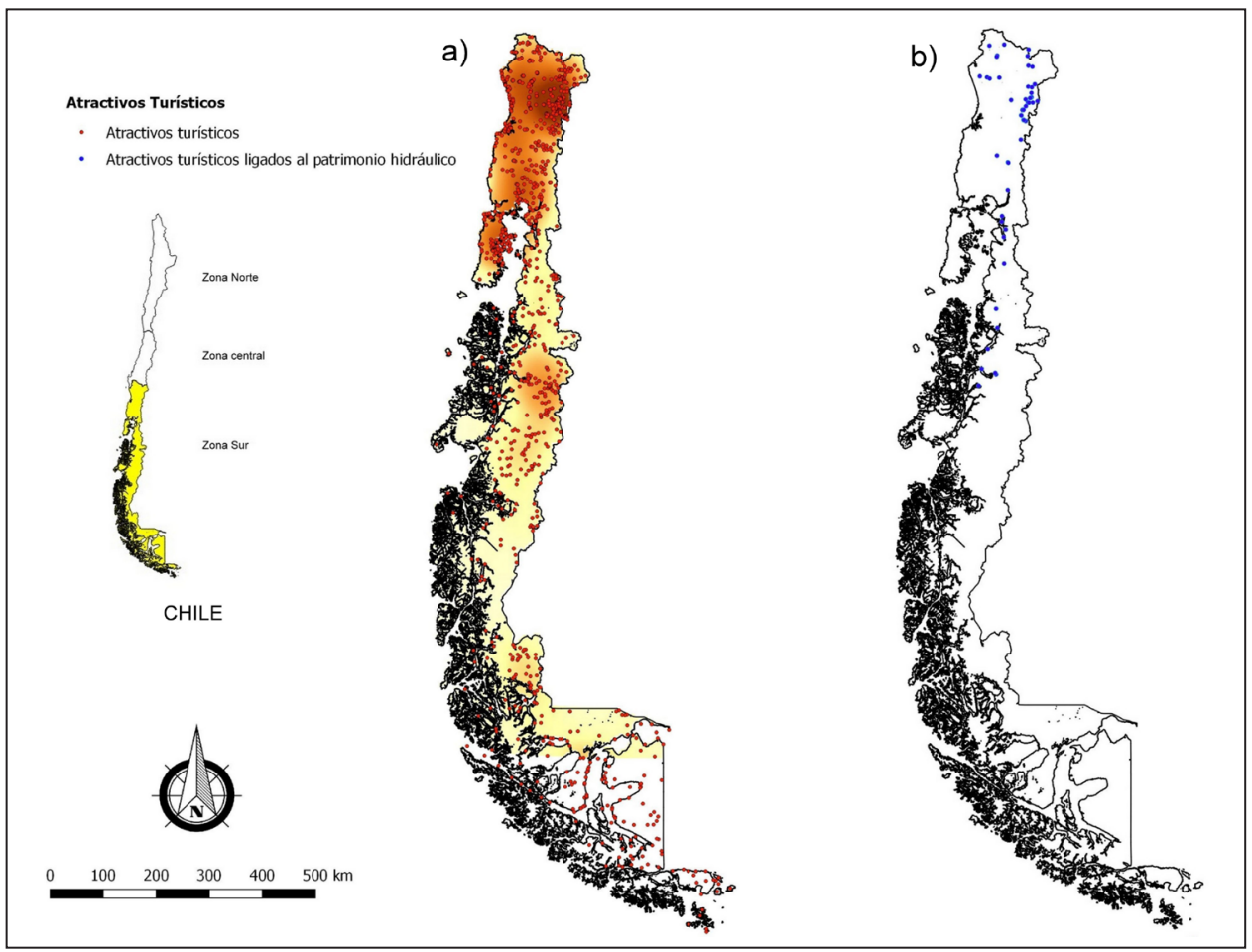

Fuente: Elaboración propia a partir de los datos de SERNATUR. 


\section{PROMOCIÓN TURÍSTICA DIGITAL DEL SERNATUR Y LAS INTENDEN- CIAS REGIONALES}

\subsection{Zona norte}

En lo que concierne a los atractivos naturales, la diversidad y número de los elementos señalados es muy amplia, entre los que destacan los Parques y Reservas Nacionales. Se mencionan, del mismo modo, numerosos espacios individualizados y elementos, como son: volcanes, oasis, lagos, geiseres, salares, valles, cerros, cuevas, playas y paisajes costeros. Además, como no podía ser de otra manera, el desierto supone un atractivo notablemente promocionado, si bien, en parte, esta es la principal diferencia de este territorio con otras áreas del país y elemento fundamental ligado al interés de sus cielos, cuya observación astronómica se explota en la gran mayoría de provincias que componen esta zona, destacando los puntos de observación establecidos en el Cerro Tololo, Gemini, Las Campanas, La Silla, Cerro Mamalluca y Collowara, así como la designación al Valle del Elqui como "Santuario internacional de cielos oscuros". Por último, cabe señalar el Museo Entomológico e Historia natural de Vicuña.

En cuanto a los atractivos culturales, estos completan un inventario variado en el que sobresale las menciones a la Fiesta de la Tirana, la Fiesta de la vendimia de Codpa y la Fiesta de la Virgen de Ayquina, así como la arquitectura en adobe de algunos elementos destacados, caso de la Iglesia de San Pedro de Atacama. De igual manera, la presencia de culturas prehispánicas como la aymara, chinchorro, atacameña y diaguita, son reclamos utilizados por su importancia etnográfica e histórica; aquí destacan el Museo etnográfico de Caspana y la promoción de las las leyendas y espíritus en Parinacota que forman parte de estas culturas indígenas. Igualmente, la gastronomía, tanto de las zonas de interior como de las costeras, es intensamente subrayada, como también resulta un atractivo cultural para el Valle del Elquí, Gabriela Mistral, Premio Nobel de literatura.

Por otro lado, en la zona norte, las referencias a atractivos históricos son numerosas. De este modo, se pone énfasis, de manera notable, en la historia ligada a las momias de Arica y Parinacota, recogida en diferentes instalaciones museísticas señaladas: Museo de Sitio “Colón 10”, Museo de Momias Chinchorro o Museo Arqueológico de San Miguel de Azapa, entre otros. En esta última población, además se encuentra la Pucará de San Lorenzo del siglo II. Las ruinas de la minería salitrera suponen otro atractivo incentivado, entre los que sobresalen las Salitreras de Humberstone y Santa Laura (Patrimonio de la Humanidad), si bien en línea con este aprovechamiento turístico de las actividades extractivas, se promociona la Mina Chuquicamata. A nivel urbano, tanto Arica, como Chiu Chiu, La Serena, Coquimbo, Parinacota y Vicuña, se citan con motivo de los distintos inmuebles y monumentos de interés arquitectónico e histórico con los que cuentan, además de subrayar el interés del Museo Histórico de Vicuña y el pueblo de Paihuano por su arquitectura colonial. Igualmente, se promocionan las iglesias de La Serena por su arquitectura colonial, la de Chiu Chiu de arquitectura indígena y las de Parinacota y Caspana del siglo XVII.

En lo concerniente a los atractivos de ocio, los balnearios (playas) de Arica, Iquique y Coquimbo, son, sin duda, uno de los recursos a los que se alude reiteradamente, además 
de por su posibilidad de baño, también por constituir puntos ideales para la práctica de deportes costeros, destacando el surf y buceo en Iquique. En esta línea, las actividades deportivas acuáticas son también promocionadas en los embalses de Limarí y Fray Jorge, a lo que, únicamente, deben sumarse las referencias al Faro Monumental de La Serena, la Avenida del Mar de Coquimbo, el casino de Arica y la posibilidad de realizar vuelos en parapente sobre la Playa Cavancha en Iquique.

Por último, entre los atractivos rurales distinguidos, las viñas y el enoturismo acaparan gran parte de las menciones, destacando las referencias a los Valles del Elquí, Copiapó y Huaso, productores de vinos, pisco y otros licores. Igualmente, sobresalen las citas a valles irrigados donde se cultivan productos exóticos, caso de Arica, San Miguel de Azapa, Iquique y Pica, entre otros, y las zonas agrícolas de Ovalle, Quebrada del Jere, Alto del Carmen, zona central de La Serena y Coquimbo. Además, se promociona el turismo rural entorno a Coquimbo y el agroturismo en el Valle del Huaso.

\subsection{Zona central}

Según la información obtenida, en esta área los atractivos naturales son promocionados con ahínco. Los numerosos espacios naturales protegidos (reservas, parques nacionales y santuarios de la naturaleza) se ofertan junto con multitud de elementos naturales o geográficos singulares (costas, bosques nativos, cordilleras, quebradas y valles, pozones, cascadas, lagos, volcanes, dunas, humedales e islas), a lo que debe sumarse la belleza de sus paisajes, la calidad de sus cielos para la observación astronómica y la utilización de los cerros como puntos de contemplación del entorno.

En lo que tiene que ver con los elementos culturales, cabe destacar las alusiones a los distintos museos existentes ${ }^{3}$ (valgan como ejemplo, los municipales de Santiago, Pomaire y Milipilla, entre otros; la Casa Museo de Pablo Neruda y el Museo Andino de Alto Jahuel). También se señalan por su interés general algunas ciudades como Putaendo, Pomaire, Chillán y Concepción, entre otras muchas. Además la cultura indígena (especialmente la mapuche ligada a sus tradiciones, mitología y la existencia de los museos de Alta Frontera y Mapuche en la Región del Biobio), es promocionada con énfasis, como también la existencia de poblados con una fuerte preservación de las tradiciones indígenas, la gastronomía tradicional y la artesanía (textil, alfarera y en madera), y en otra léna, la importancia de las diversas universidades implantadas en este territorio.

Respecto a los atractivos históricos, los restos paleontológicos (Museo de los Mastodontes de San Vicente de Tagua Tagua y Cocholgue, especialmente) y arqueológicos se citan de manera profusa, junto con el arte prehistórico existente, caso de los petroglifos (Cabildo y R.N. Río Los Cipreses). Del mismo modo, son muy importantes los distintos museos temáticos o municipales en cuyas colecciones se ofrece una información histórica de enorme valor, valgan como ejemplos el Museo Colchagua y el Museo Histórico Yerbas Buenas. También se hace alusión de manera notable a la historia ligada a diversos espacios y monumentos de algunas poblaciones (Viña del Mar, San José del Maipo, Vichuquen, Talca y Curicó, Talcahuano, Melipilla, Rancagua y Concepción, entre otras) la arquitectura

3 Instalaciones con valor histórico-cultural. 
típica heredada de los distintos pueblos que vivieron en este territorio (Valparaíso, Viña del Mar, Petorca, Zapallar, Rancagua, Vichuquen, Yerbas buena-Villa Alegre,...) y así como la impronta que dejó sobre el espacio y la sociedad, la minería; hecho reflejado de manera excepcional en Sewell (Patrimonio de la Humanidad) y su Museo de la gran minería del cobre, como también en el Circuito del Lota y la Mina Chiflón del Diablo.

En lo que concierne a las actividades de ocio, los deportes náuticos (surf en Maitencillo, Pichilemu y Punta Lobos y buceo en Los Molles) y balnearios (playas), acaparan gran parte de la promoción turística, si bien el turismo deportivo (deportes de invierno o turismo activo) y el termalismo (Panimavida, Anquimavida, Catillo, Valle Las Trancas, entre otros lugares), también constituyen una oferta importante, junto a parques (Bicentenario, Cerro San Juan, Ross, Ecuador,...) y eventos culturales (Concepción capital del rock), singularizándose la presencia de casinos (Viña del Mar, Colchagua y Montecillo), el gran complejo del Costanera en Santiago de Chile y la ruta de ufológica de la Región del Maule.

Por último, en lo que concierne a los recursos turísticos rurales, el enoturismo (en toda su dimensión y en las zonas de los valles de Casablanca, San Antonio, Maipo, Pirque, Central, Buín, Santa Cruz, Colchagua, Cachapoal y Quillón, como máximos exponentes), es, sin duda, el principal atractivo al que se hace alusión, estando además fomentado por las Rutas del vino del Valle del Maule y del Valle del Curicó y Rauco, así como por la Fiesta de la Vendimia celebrada en Santa Cruz. Mientras, de manera secundaria se destaca la presencia de cultivos exóticos (cerezas y frambuesas en la comuna de Romeral y papayas en Duao, ambas en la Región del Maule) y la apicultura en Pichuncavi, al igual, que el interés turístico de los poblados rurales de Ligua, Cabildo, Petorca y Cajón del Maipo.

\subsection{Zona sur}

La extensión y buena conservación de los espacios naturales de este territorio lo hace realmente atractivo al turista, que puede disponer de espacios vírgenes prácticamente inalterados entre los que. destacan los numerosos Parques Nacionales y distintos elementos naturales de interés. En este sentido, las masas de agua lagunares predominan en el paisaje y también dentro del cómputo global de elementos mencionados. Igualmente se hace alusión a los volcanes y glaciares, como también a los fiordos, termas, islas y la existencia de bosques milenarios en los que, todavía hoy, vive la araucaria. Además, se citan como puntos atractivos por sus paisajes, las poblaciones de Puerto Natales y Punta Arenas, así como Cabo de Hornos, Archipiélago de Chiloé, Canal del Beagle, Cordillera Darwin y la Antártica, completando el compendio, la "Ruta de la pesca, termas y ventisqueros de Palena" y la "Ruta Austral: Puelo-Futalenfú", con cuya realización se puede contemplar gran parte de los paisajes naturales de este espacio.

En lo que respecta a los atractivos culturales, destacan sobre el resto las referencias que se hace a la cultura mapuche, hecho muy ligado al énfasis puesto en las ferias artesanales y la gastronomía. Igualmente, se destaca la cultura musical de Concepción, los mitos y leyendas de Chiloé y los ritos locales de Lonquimay. Además, en lo que se refiere a los espacios museísticos, tan solo se señalan el Museo de Arte Contemporáneo de Valdivia y el de Fernando Cordero Rusque en Tierra del Fuego. Del mismo modo, se debe nombrar 
el Festival de la lluvia de Puerto Varas y el mercado fluvial de Valdivia. Puerto Montt y Angelmó se singularizan por su condición de ciudades portuarias y de tradición pesquera, si bien también se promociona la "Ruta Cruce de Lagos", en la que se visita un molino hidráulico, y la Feria de Artesanía de la Región de Aysén.

En cuanto a los atractivos históricos, existen numerosos enclaves de importancia, valga como ejemplo Chiloé, declarada Patrimonio de la Humanidad, y donde destaca la "Ruta de las Iglesias". Valdivia y Corral sobresalen igualmente por su patrimonio histórico y cultural, entre el que se pueden citar la presencia de fortificaciones del periodo colonial. También la arquitectura de origen germano de las poblaciones localizadas en las riberas de los lagos Llanquihue y Todos los Santos, Puerto Octay y Puerto Varas, entre otras, constituyen otro de los principales atractivos del sur. En esta línea, en Osorno se cita su catedral y el Fuerte de la Reina Luisa. Asimismo, también se enfatiza la importancia de la minería en Lota, con el exponente de la Mina Chiflón del Diablo y el Museo histórico de Lota.

Por último, como atractivos de ocio se promocionan las playas de Puerto Montt, Puerto Varas y Angelmó, las pistas de esquí de "El Fraile", Pucón y Chillán, la pesca deportiva en Aysén, Lican Ray, Lago Lanquihue, Coyahique, etc. y el turismo activo derivado del desarrollo del Sendero de Chile. Otra singularidad son las referencias de terapias con crema de murtilla o leche de cabra, así como el programa musical y teatral de Frutillar, y se cita el Casino de Temuco y la Villa Turística Río Serrano.

De esta forma el SERNATUR y las Intendencias regionales, a pesar de que incluyen en su promoción turística un vasto compendio de atractivos naturales, culturales, históricos, de ocio y rurales, la inclusión de menciones al patrimonio hidráulico son insignificantes. En la zona norte se citan algunos oasis existentes en Iquique, la presencia de valles irrigados, sin que se mencionen las infraestructuras empleadas para ello, la existencia de termas en el área de Limarí-Fray Jorge y la realización de deportes náuticos en los embalses de esta última provincia. En la zona central, aparecen referencias a las termas de Colina y Baños Morales y del Plomo en la Región Metropolitana, Flaco en la de O’Higins, las de Panimavida, Quinamavida y Catillo en la de Maule, y las de Chillán en la del Biobio. También se cita el Embalse del Yeso en la Región metropolitana, el Puente Cardenal Silva Henríquez en la de Maule y las Ruedas de Larmahue en la de O’Higgins. Por último, citar que en la zona sur únicamente se destaca el Festival de la lluvia de Puerto Varas.

\section{EL PATRIMONIO HIDRÁULICO EN LA BIBLIOGRAFÍA}

No cabe duda de que Chile es un territorio habitado desde tiempos pretéritos y en el que los distintos grupos humanos que vivieron en él dejaron su impronta. De este modo, la canalización y aprovechamiento de las aguas que corrían por quebradas, valles y ríos para el consumo humano, el desarrollo de la agricultura y el abastecimiento industrial, fue una tarea que propició transformaciones del paisaje y las sociedades, como así se percibe al analizar la bibliografía.

En este sentido, las primeras evidencias de canalizaciones se corresponden con infraestructuras indígenas, obras que fueron incrementadas por los incas y llevadas al máximo exponente durante la etapa colonial (en algunos casos desplazando la cultura de los pueblos originarios) y postcolonial cuando los conocimientos técnicos y herramientas 
disponibles posibilitaron la construcción de obras de mayor envergadura. De este modo, prácticamente en todo el espacio chileno existen un gran número de canales de distinta antigüedad que son un claro reflejo de la adaptación del hombre al medio y que, sin embargo, no son consideradas un atractivo cultural, al igual que los sistemas de regadío citados por distintos autores y localizados en los valles de algunos de los principales ríos de Chile: Laja, Maipo, Loa y San Pedro, por ejemplo, así como los de Pencahue, Ligua, Conchalí, y los existentes en Victoria-Traiguén-Lautar, Faja Maisan, Chile Chico, Almahue y Socoroma, y los oasis de Tilomante, Pica y Guatacondo (Castro et. al. 1992; Sandoval, 2003; Palerm, 2010; Sahady et al. 2013 y 2015 y Bolados y Babidge, 2017). Del mismo modo, es ineludible incluir las referencias al Canal San Carlos (Astaburuaga, 2004) y a las antiguas acequias de Santiago que abastecían a la población, los pequeños huertos urbanos y las zonas agrícolas extraurbanas; canales que se conocían con los nombres de La Cañada, Acequia de Ntra. Sra. Del Socorro (Cañada de San Francisco), del Cacique Vitacura y Canal Negrete o Cañada García de Cáceres (Figueroa, 2009; Rosas y Pérez, 2013 e Hidalgo y Vila, 2015), entre otros, así como las acequias existentes en la Calle San Diego y en la zona próxima a la Escuela militar (Hidalgo y Vila, 2015) o la del Cerro San Cristóbal (Sahady et. al. 2014) y los canales de San Miguel o Zanjón de la Aguada (Hidalgo y Vila, 2015).

Otra de las infraestructuras señaladas con asiduidad son los embalses, como en el caso del trabajo de Sandoval (2003), espacios cuya obra de ingeniería hidráulica en ocasiones queda oculta tras los paisajes que se generan a partir de la lámina de agua que acumula el represamiento. También el cultivo en terrazas es destacado, identificando esta modalidad agrícola en Zapahuira (Poblado Inca), San Pedro de Atacama, Calama, Quillagua, Cluta, Azapa, Codpa, Camarones y Comiño. Además, se señalan las distintas formas de riego empleadas en Socoroma (chipallas, surcos, pampa y bateíta) y el riego de caracol utilizado en el Valle de Azapa.

Por otro lado, los molinos hidráulicos, son otro de los bienes inmuebles patrimoniales sobre los que versan distintas publicaciones, citándose su existencia en Chiloé (Bravo et. al. 2016 y Sahady et. al. 2016), Pichidegua, Pichilemu (Bravo et. al., 2017), Victoria (Rodríguez, 2015), Curicó, Chillán, Yungay, Nahuelbuta, La Unión, Contolumo Traiguén, Carahue, Frutillar, Puerto Varas y en la propia ciudad de Santiago, donde se documenta la presencia histórica de los molinos propiedad de Rodrigo de Araya, Bartolomé Flores, Juan Dávalos Jofré y Rodrigo Quiroga (La Chimba), así como aquellos conocidos como Molino de Santo Domingo, San Agustín, Chavarría y María Flores (Sahady et. al. 2014). Construcciones que al igual que las azudas de Larmahue (De las Casas, 2007; Sahady, 2011; Bravo et. al., 2013 y Sahady et. al. 2013 y 2015), poseen un componente inmaterial e ideológico de enorme valor patrimonial.

Otros elementos citados son los Tajamares del río Mapocho a su paso por la capital chilena (Figueroa, 2009), para los cuales se intentó poner en marcha un museo hoy abandonado, las obras de desecación de la Laguna Tagua Tagua en 1838, el proyecto de interconexión de los valles de Vilasamanani y Socoroma (1000-1500 d.C.) (Hurtado, 2010), las termas de puritana y los puentes santiaguinos sobre el Canal de San Miguel y sobre el río Mapocho (Puente de palo y de Cal y canto), así como también se identifica el Puente viejo de Colemu. 
En lo que respecta a la parte inmaterial, existió en todo momento una organización encargada del desarrollo de las obras y la gestión del agua, ya fuese de una manera más o menos compleja y sobre la que han escrito, entre otros, Arumi y Oyarzún (2006), Larraín (2006), Baeza (2008), Palerm (2010) y Arumi et. al. (2014). Las instituciones de los Juzgados de Aguas en época colonial y las figuras del Juez de Aguas, Juez de Río y Juez de Policía Rural, son, sin duda, algunas de las más reconocidas dentro de los sistemas hidráulicos de Chile, así como la gestión realizada desde los Cabildos. En época más reciente, las Asociaciones de Canalistas creadas al amparo de la Ley 2139 de 1908, las Comunidades de Aguas, las Organizaciones de Usuarios del Agua (OUA), las Juntas de Vigilancia y la Confederación de Canalistas de Chile (1949), son, sin duda, los principales encargados de velar por la captación, canalización y reparto del agua en el país, y de forma concreta para el caso del río Maipo, la Sociedad de Riegos del Maipo. También juegan un papel importante la Comisión Nacional de Riego (CNR, 1975) llamada con posterioridad Dirección de Obras Hidráulicas (DOH), hasta 1997 nominada Dirección de Riego. Del mismo modo, cabe destacar aquí las referencias hechas a la distribución del agua mediante turnos de agua o mitas (Castro et. al. 1992 y Hurtado, 2010) y la gestión en lugares de profunda escasez hídrica (Pourrut y Núñez, 1995 y Sepúlveda, 2015).

También es interesante la legislación implantada para regular el aprovechamiento hídrico y el desarrollo de explotaciones y obras en las distintas épocas históricas, en algunos casos con una fuerte influencia de la herencia de la normativa hispánica (Arumi et. al. 2014). Así, en base a los trabajos de Castro (1991 y 1997), Arumi et. al. (2014), Palerm (2010) y Nicolás (2017), se pueden destacar las siguientes normas: Leyes de Indias (compendio del S.XVII que recogía parte de las leyes indígenas, entre las que se encontraban aquellas en materia de gestión de aguas); Decreto supremo de 1819 (primer texto en el que se definen algunos conceptos básicos como la figura del regador, la venta de aguas y la bocatoma); Código Civil (1885); Ley 2139 (1908) marco legal de las Asociaciones de Canalistas, Código de Aguas (1967), Código de Aguas (1981), Ley de Fomento de Inversión Privada en obras de riego y drenaje (1985) o Ley indígena (1993), cuyo Artículo 64 es el Relativo a las aguas y la creación de las comunidades de aguas.

Además, no resulta extraño que entorno al agua y los elementos hidráulicos que interactúan con ella, de una manera u otra, se haya generado una cultura del agua cuyas manifestaciones son de un profundo interés, más, si cabe, en un territorio donde el simbolismo de las comunidades indígenas está estrechamente ligado al medio natural y al uso que se hace de sus recursos de una manera física y espiritual, como en el caso de la limpia de los canales en el mundo andino y lugares como Camar, Peine, San Pedro de Atacama y Socoroma (Bolados y Babidge, 2017). Igualmente, se señala la celebración de una serie de festividades ligadas a elementos patrimoniales hidráulicos como son: la Fiesta de las ruedas de Larmahue (Pichidegua) (Bravo et. al., 2013), la Fiesta de la molienda (Curaco de Vélez) (Bravo et. al., 2016), el Carnaval del Agua (Castro et. al. 1992) y la Fiesta de la vendimia realizada en el Molino Santa Amelia (Bravo et. al. 2018).

Por último, destacar que se presentan evidencias fehacientes de un aprovechamiento turístico puntual de algunos de estos recursos patrimoniales ligados al agua. De este modo, se han identificado la Ruta de los molinos de agua (Chiloé) (Bravo et. al. 2016), la Ruta de San Andrés (Pichilemu) (Bravo et. al. 2017), la Ruta del agua (Pichidegua) (Bravo et. 
al. 2018) y una Ruta turística con 10 molinos (Península de Rilán), además de la presencia del Museo de la Cultura Campesina y Huasa instalado en el inmueble del Molino de Santa Amelia (Bravo et. al. 2018) y la utilización de algunos molinos hidráulicos como hospederías o puntos de venta de productos tradicionales.

\section{CONCLUSIONES Y PROPUESTAS}

Se pude afirmar que en Chile el patrimonio hidráulico no se considera de manera suficiente como recurso cultural y turístico y así ha quedado demostrado según:

- La baja representación de estos elementos dentro del total de monumentos catalogados por el CMN (65 de un total de 1689 inventariados, es decir, un $3,8 \%$ ) y su escasa diversidad.

- La reducida representación dentro del catálogo de "Atractivos turísticos" identificados por el SERNATUR (138 de un total de 4413, lo que supone un 3,13\% del total) y de cuyo análisis zonal se desprende que este mínimo interés es una cuestión nacional ya que la consideración de estos atractivos ligados al patrimonio hidráulico es igualmente insignificante en las tres zonas definidas: en la zona norte 29 elementos de un total de 1334 (2,2\%), en la zona central la relación es de 53 de $1748(3 \%)$, y, en la zona sur 56 de $1331(4,2 \%)$.

- Y, en tercer lugar, por una insignificante inclusión de estos bienes patrimoniales en la promoción turística digital realizada desde dos organismos públicos, SERNATUR e Intendencias regionales, en cuya oferta apenas aparecen representados elementos ligados al agua.

De acuerdo con esto, queda expuesto que desde las instituciones estatales y regionales, el patrimonio hidráulico, tanto físico como inmaterial, es el gran olvidado dentro del ámbito de valoración cultural, como también de los recursos turísticos potencialmente atractivos y explotables económicamente; incluso, se ha demostrado que gran parte de los bienes ligados al agua catalogados quedan fuera de los circuitos turísticos definidos por el SERNATUR, pese a que algunos se encuentran en áreas próximas.

En este estado y en base a los resultados expuestos, puede llegarse a la errónea conclusión de que Chile dispone de un patrimonio hidráulico limitado y poco interesante. Nada más lejos de la realidad, como se deduce de la revisión bibliográfica y con cuya lectura se comprueba la existencia de un interesante compendio de recursos a lo largo y ancho de todo el país. Bienes que en ocasiones sí se tienen en consideración mientras que en otras carecen de reconocimiento pese a que, sin duda, son, igualmente, interesantes.

De esta forma, únicamente con las referencias halladas en la bibliografía consultada, se ha logrado distinguir toda una serie de infraestructuras hidráulicas y elementos inmateriales que, por sí solos, constituyen un patrimonio hidráulico de valor y merecen un reconocimiento, bien sean obras todavía presentes como aquellas que han desaparecido pero cuya existencia fue y es relevante para explicar el Chile actual.

En consecuencia, considerando que el patrimonio hidráulico lo constituyen una serie de manifestaciones, materiales e inmateriales, que reflejan parte de la actividad humana sobre el territorio y la manera en que sus pobladores se han adaptado al medio desde época histórica, es evidente que este conjunto de bienes, son de interés cultural y patrimonial, 
por lo que, ante la falta de consideración cultural y turística del patrimonio hidráulico que atesora Chile, se propone:

- Realizar un inventario nacional de bienes patrimoniales ligados a la cultura hidráulica, tanto material como inmaterial, a una escala de investigación local, regional y nacional.

- Crear figuras de protección estatal para estos elementos patrimoniales que permitan conocer, tanto su grado de interés cultural, como justificar el valor de su inclusión en proyectos de recuperación, conservación y divulgación.

- Incentivar la investigación científica (mediante jornadas de investigación, coloquios, conferencias, estudios monográficos,...) enfocada al análisis de este tipo de patrimonio y las posibilidades del mismo como potenciales recursos turísticos generadores de riqueza económica y cultural especialmente en las zonas rurales.

- Estimular la promoción turística del patrimonio hidráulico, tanto de manera individualizada, por su condición de auténticos hitos culturales, históricos y etnográficos, como creando circuitos turísticos que los integren como un atractivo o incorporándolos a aquellos recorridos preexistentes.

- Incluir esta tipología de patrimonio en la oferta de actividades culturales y lúdicas con el objeto de ayudar a mejorar la percepción y valoración que la población tiene de estos bienes.

\section{REFERENCIAS}

ARROYO ORELLANA, D.I. (2009): Las asociaciones de usuarios de aguas en Chile durante el siglo XIX y primera mitad del siglo XX: 1800-1950. TFG, Universidad de Chile.

ARUMI, J.L., MELO, O., NUÑEZ, J. y BILLIB, M. (2014): «Riego y Usuarios del Agua en Chile. Desde la revolución a la evolución», en Irrigation, Society and Landscape. Tribute to Tomas F. Glick. Valencia, Editorial Universidad Politécnica de Valencia, pp. 661-671.

ARUMI RIBERA, J.L. y OYARZÚN LUCERO, R.A. (2006): «Las aguas subterráneas en Chile», Boletín Geológico y Minero, n 117, 1, pp. 37-45.

ASTABURUAGA, R. (2004): «El agua en las zonas áridas de Chile». $A R Q, \mathrm{n}^{\circ}$ 57, pp. 68-73.

BAEZA VÁSQUEZ, K. (2008): Administración privada del agua en Chile a través de Organizaciones de Usuarios. Estudio exploratorio en organizaciones de base del Estero Chimbarongo, Valle de Colchagüa, VI Región. TFG, Universidad de Chile.

BOLADOS GARCÍA, P. y BABIDGE, S. (2017): «Ritualidad y extractivismo: la limpia de canales y las disputas por el agua en el Salar de Atacama-norte de Chile», Estudios atacameños, $\mathrm{n}^{\circ}$ 54, pp. 201-216.

BRAVO SÁNCHEZ, J.M., GIL MESEGUER, E. y SAHADY VILLANUEVA, A. (2018): «Molinos de agua en la región de O’Higgins, Chile. Revaloración de un patrimonio hidráulico y campesino a través del turismo rural», Aportes y transferencias, $\mathrm{n}^{\circ} 16$, 1, pp. 47-69. 
BRAVO SÁNCHEZ, J.M., QUILODRÁN RUBIO, C. y SAHADY VILLANUEVA, A. y AGUIRRE GONZÁLEZ, M. (2016): «Molinos de agua de Chiloé. La pervivencia de una economía campesina en tiempos de globalización a través del turismo patrimonial, Región de Los Lagos, Chile», Anales de la Sociedad Chilena de Ciencias Geográficas 2015 , pp. 27-34.

BRAVO SÁNCHEZ, J.M. y SAHADY VILLANUEVA, A.S; QUILODRÁN RUBIO, C. (2013). «Azudas en Chile: un vernáculo sistema de riego en tierras de secano», Papeles de Geografia, $\mathrm{n}^{\circ}$ 57-58, pp. 69-84.

BRAVO SÁNCHEZ, J.M.; SAHADY VILLANUEVA, A.S. y QUILODRÁN RUBIO, C. (2017): «Molinos hidráulicos de Pichilemu, Chile: Pervivencia de un patrimonio campesino», Gremium, vol. 4, no 8 , pp. 33-44.

BUDDS, J. (2012): «La demanda, evaluación y asignación del agua en el contexto de escasez: un análisis del ciclo hidrosocial del valle del río La Ligua, Chile», Revista de Geografía Norte Grande, $\mathrm{n}^{\circ}$ 52, pp. 167-184.

CASTRO LUCIC, M. (1997): «Agua, derechos y cultura en los Andes del norte de Chile. Un enfoque desde la Antropología Jurídica», Chungara, vol. 29, no 1, pp. 63-80.

CASTRO, M.; BAHAMONDES, M.; JAIME, M.; MENESES, C.; NAVARRETE, C. (1991): «Cultura, tecnología y uso del agua en un pueblo andino del norte de Chile», Revista Chilena de Antropología, no 10, pp. 45-69.

CASTRO, M.; BAHAMONDES PARRAO, M.; JAIME, M. (1992): Cultura hídrica: un caso en Chile. La Habana (Cuba), Oficina Regional de Cultura para América Latina y el Caribe.

DE LAS CASAS GÓMEZ, A. (2007): «Las ruedas de Larmahue: pervivencia en Chile de un sistema hidráulico español», en V Congreso de Historia de la Construcción (Burgos), pp. 205-216.

DOUROJEANNI, A. (1999). Debate sobre el Código de Aguas de Chile. Congreso Nacional de la República de Chile, $1^{a}$ Mesa redonda sobre el uso sustentable de los recursos hídricos. Valparaíso (Chile), CEPAL.

ERAZO, MANUELA B.; GARAY-FLÜHMANN, R. (2011): «Tierras secas e identidad. Una aproximación cultural a las prácticas de subsistencia de las comunidades campesinas del semiárido: Provincia de Elqui, Chile», Revista de Geografía Norte Grande, $\mathrm{n}^{\circ} 50$, pp. 45-61.

FERNÁNDEZ DOMINGO, E. (2015): «Estudio sobre la génesis y la realización de una estructura urbana: la construcción de la red de alcantarillado de Santiago de Chile (1887-1910)», Historia (Santiago), vol. 48, no 1, pp. 119-193.

FIGUEROA SALAS, J. (2007): «De la forma ruris a la forma urbis. Elementos configuradores del sitio de la ciudad», $A+C, \mathrm{n}^{\circ} 2$, pp. 9-25.

FIGUEROA SALAS, J. (2009): «Las aguas en la estructura urbana de Santiago de Chile. Hacia un urbanismo de fluidos», Boletín $C F+S, \mathrm{n}^{\circ}$ 42/43, pp. 57-67.

FIGUEROA SALAS, J. (2012): «Las trazas de agua y el modelamiento de la planta urbana, en La evolución morfológica de la ciudad de Santiago de Chile. Trayectorias de la Ciudad Moderna», IV Seminario Docomomo. Concepción, Chile, pp. 39-43

FIGUEROA SALAS, J. (2014): «Las trazas del agua y la construcción del paisaje agrícola», Revista AUS, n ${ }^{\circ} 13$. pp. 15-18. 
FLORES ARAYA, F. (2008): «Las trazas del territorio desértico. Los espacios arquitectónicos de Atacama», Revista Arteoficio, n 7, pp. 31-37.

HIDALGO, J. (1985): «Proyectos coloniales inéditos de riego del desierto: Azapa (Cabildo de Arica, 1619); Pampa Iluga (O’Brien, 1765) y Tarapacá (Mendizabal, 1807)», Chungará, $\mathrm{n}^{\circ} 14$, pp. 183-220.

HIDALGO HERMOSILLA, G.; VILA MUGA, W. (2015): "Calles -que fueron- caminos: intensificación de la trama de calles al sur de la alameda en Santiago de Chile hasta fines del siglo XIX», Historia (Santiago), vol. 48, n 1, pp. 195-244.

HURTADO QUIÑONES, A. (2013): «Patrimonio cultural y turismo en San Pedro de Atacama, Chile», Campos en Ciencias Sociales, vol.1, nº 2, pp. 299-311.

LARRAÍN, S. (2006): «El agua en Chile: entre los derechos humanos y las reglas del mercado», Polis. Revista Latinoamericana, $\mathrm{n}^{\circ}$ 14, pp. 1-20.

MÁRQUEZ, F.; TRUFFELLO, R. (2013): «Geografías de un territorio de frontera: La Chimba, Santiago de Chile. Siglo XVII - XXI», Revista de Geografía Norte Grande, $\mathrm{n}^{\circ} 56$, pp. 75-96.

MARTOS NÚÑEZ, E.; MARTOS GARCÍA, A. (2013): «Ecoficciones e imaginarios del agua y su importancia para la memoria cultural y la sostenibilidad», Alpha (Osorno), n 36 , pp. 71-91.

NICOLÁS ARTERO, C. (2015): «Memorias de agua. Las organizaciones de usuarios frente a la escasez en la cuenca de Chicureo, Colina (1962-2015)», Revista Tiempo Hist., $\mathrm{n}^{\mathrm{o}} 10$, pp. 87-107.

OLAVE FARÍAS, D. (2004): «Paisaje, turismo y patrimonio en Chile central», Espacio y Desarrollo, $\mathrm{n}^{\circ} 16$, pp. 44-59.

ORELLANA, M. M. (2006): «Murmullo de Agua: Colegio técnico experimental Aymara en Putre. Agro-Ganadero/Turismo-Patrimonio», Revista de Urbanismo, $\mathrm{n}^{\circ}$ 15, pp. 87-106.

PALERM VIQUEIRA, J. (2010): «Comparative history of irrigation water management, from the sixteenth to twentieth centuries: Spain, Mexico, Chile, Mendoza (Argentina) and Peru», Water Policy, vol. 12, pp. 779-797.

PÉREZ OYARZUN, F.; ROSAS, J.; VALENZUELA, L. (2005): «Las aguas del centenario», $A R Q$ (Santiago), $\mathrm{n}^{\circ}$ 60, pp. 72-74.

PILQUIMÁN, M.; SKEWES, J.; GUERRA, D.; HENRÍQUEZ, C. (2016): «Culturas originarias y turismo comunitario. Espacios interdisciplinarios e interculturales para la revitalización del patrimonio en el mundo Mapuche (Tralcao sur de Chile)», Gestión Turística, no 26, pp. 7-20.

POURRUT, P.; NUÑEZ, L. (Edit.) (1995): Agua, ocupación del espacio y economía campesina en la región atacameña. Aspectos dinámicos. Antofagasta, Universidad Católica del Norte y ORSTOM.

RODRÍGUEZ DOMÍNGUEZ, C. (2015): «Patrimonio de la industria molinera en La Araucanía: el granero de Chile», Andes del Sur, nº 3, pp. 1-25.

ROSAS VERA, J.; PÉREZ VILLALÓN, E. (2013): «De la ciudad cerrada de los conventos a la ciudad abierta de los espacios públicos: Santiago 1710-1910», Revista de Geografía Norte Grande, n 56, pp. 97-119. 
SAHADY VILLANUEVA, A. (2011): «Las azudas de Larmahue: una singular manifestación del ingenio humano para regar cultivos en tierras de secano», Revista de Urbanismo, $\mathrm{n}^{\circ} 25$, pp. 5-25.

SAHADY VILLANUEVA, A., BRAVO SÁNCHEZ, J. y QUILODRÁN RUBIO, C. (2013, a): «Las Azudas de Larmahue Arquitectura de ruedas en tierras de secano, en pleno corazón campesino de Chile», ARQUISUR, $\mathrm{n}^{\circ}$ 1, 3, pp. 78-95.

SAHADY VILLANUEVA, A., BRAVO SÁNCHEZ, J. y QUILODRÁN RUBIO, C. (2013, b): «La identidad local expresada, a través de creaciones artesanales propias, en dos paisajes campesinos: las azudas de Murcia, en España y las azudas de Larmahue, en Chile», América Patrimonio, n ${ }^{\circ}$ 5, pp. 40-57.

SAHADY VILLANUEVA, A., BRAVO SÁNCHEZ, J. y QUILODRÁN RUBIO, C. (2015, a): «Molinos de agua en Chile y España: la creación artesanal al servicio del paisaje campesino», en VII Seminario Internacional de Investigación en Urbanismo, Barcelona-Montevideo, Departamento de Urbanismo y Ordenación del Territorio. Universidad Politécnica de Cataluña.

SAHADY VILLANUEVA, A., BRAVO SÁNCHEZ, J. y QUILODRÁN RUBIO, C. (2015, b): «Las Azudas de Larmahue, en Chile: ingeniosa solución artesanal para capturar el escaso recurso hídrico en tierras de secano», Identidades: territorio, proyecto, patrimonio, $\mathrm{n}^{\circ} 5$, pp. 99-113.

SAHADY VILLANUEVA, A., BRAVO SÁNCHEZ, J. y QUILODRÁN RUBIO, C. (2017): «Azudas de Larmahue: al rescate del recurso hídrico en medio de un terreno secano, en pleno valle del Cachapoal, Sexta Región», AUS, nº 12, pp. 18-21.

SAHADY VILLANUEVA, A., BRAVO SÁNCHEZ, J. y QUILODRÁN RUBIO, C. (2016): «Patrimonio en peligro de extinción: los molinos de agua en Chiloé». AUS, no. 20, pp. 28-33.

SAHADY VILLANUEVA, A., BRAVO SÁNCHEZ, J. y QUILODRÁN RUBIO, C.; SZMULEWICZ, P. (2014): «Al rescate de los molinos de agua en Chile», VI Congreso Latinoamericano de Investigación Turística Neuquén, 25-27 de Septiembre de 2014, pp. 1-18.

SANDOVAL JEIRA, J. (2003): El riego en Chile. Santiago de Chile (Chile), Gobierno de Chile, Ministerio de Obras Públicas, Dirección de Obras Públicas.

SEPÚLVEDA RIVERA, I., MOLINA OTÁROLA, R., DELGADO-SERRANO, M.M. y GUERRERO GINEL, J.E. (2015): «Aguas, riego y cultivos: cambios y permanencias en los ayllus de San Pedro de Atacama», Estudios Atacameños, n 51, pp. 185-206.

SOTO ACUÑA, C.E. (2011): El monumento histórico ruedas/azudas de Larmahue: impacto social y territorial del uso de agua para riego en el Canal Almahue. Comuna Pichidegua, Región de O’Higgins. Tesis de Pregrado, Universidad de Chile. 
